\title{
COVID-19 Pandemic Impact on Orthopaedic Trauma Practice: A Global Perspective
}

\author{
Abdallah S Al-Omran \\ Department of Orthopaedic Surgery, College of Medicine, Imam AbdulRahman Bin Faisal University Dammam and King Fahd Hospital of the \\ University, AlKhobar, Saudi Arabia \\ Correspondence: Abdallah S Al-Omran, King Fahd Hospital of the University, POBox 4007I, AlKhobar, 3I952, Saudi Arabia, Email alomranabdal- \\ lahs@gmail.com
}

Background and Objective: We conducted a systematic review to evaluate the global impact on orthopaedic trauma admissions during the COVID-19 crisis and compare it to that in Saudi Arabia.

Methods: We conducted an extensive search of the PubMed and the Cochrane Central Register of Clinical Trials databases for articles published on orthopaedic trauma during the pandemic. We used the terms "orthopaedic trauma", "coronavirus", "covid-19", and "Sars-cov-2" for the search. We retrieved data to assess the impact of COVID-19 on orthopaedic and trauma patients attending hospitals during the pandemic. Secondary outcomes included reports from various regions of the world, differences in patient age, gender, and comparison to the nonlockdown period. We excluded questionnaires, surveys, reviews, and meta-analyses. The studies were divided based on where they were conducted: the Americas; the United Kingdom; Europe; Asia; the Middle East; and Australia, including New Zealand.

Results: We retrieved 763 studies using the keywords and initially analyzed 70. We chose 23 studies for final analysis, which were all retrospective studies, from which we extracted $50 \%$ of our preset data. These articles included 16,383 patients who sought advice related to orthopaedic and trauma necessities during the pandemic. Before the pandemic, 61,559 patients sought advice for orthopaedic and trauma necessities. Most of the reports focused on adults, and in three studies, researchers reported on paediatric on orthopaedic patients. The average decrease in patients seeking orthopaedic and trauma assistance during the pandemic was $45.5 \pm 20.4$ (range $18.9-86 \%, p<0.001)$. The largest decrease in patients seeking advice occurred in Asia $(>60 \%)$, and the lowest occurred in Australia and New Zealand (about 20\%, $p<0.001$ ).

Conclusion: Presentations of orthopaedic trauma during the COVID-19 during pandemic lockdown was less but not as profoundly as one may have expected.

Keywords: COVID-19, orthopaedics, traumatology, pandemic, SARS-cov-2

\section{Introduction}

Wuhan, China, was the origin of the worldwide spread of COVID-19. ${ }^{1}$ The World Health Organization took the time to announce the COVID-19 pandemic was a public health emergency. ${ }^{2-4}$ The spread of the virus was quick and unabated. It took the medical community by surprise and caused immeasurable morbidity and mortality, particularly in patients with underlying comorbidities. ${ }^{5,6}$ COVID-19 was reported in 214 countries, ${ }^{7}$ and even with precautions, nations could not control the spread. Attempts to do so included lockdowns, closure of schools, and working from home in many countries, but many people still died.

The lockdowns affected many medical services, but people with emergencies still arrived at hospitals. Raman et $\mathrm{al}^{8}$ reported a negative impact on the entire health-care sector due to the lockdowns. The most affected were ambulatory practices, which declined nearly 60\%. Primary care visits decreased between $49.0 \%$ and $101.8 \%{ }^{9}$ Specialist consultations were not immune to this drop. For example, gynaecological emergency admissions dropped by $50 \%{ }^{10}$ and general surgery emergencies by $59.1 \% .{ }^{11}$ Orthopaedic and trauma consultations decreased across the board. Reports from various parts of the world presented varying figures irrespective of how severely the population was affected. The objective of this review is to evaluate the global impact on orthopaedic trauma admissions during 
the COVID-19 crisis and compare it to that in Saudi Arabia so future decisions can be made to improve health-care delivery in pandemic situations.

\section{Methods}

We conducted an extensive search of PubMed and the Cochrane Central Register of Clinical Trials databases for articles published on orthopaedic trauma during the pandemic. We used the terms "orthopaedic trauma", "coronavirus", "COVIDD-19", and "Sars-cov-2" for the search. We retrieved data to assess the impact of COVID-19 on orthopaedic and trauma patients attending hospitals during the pandemic. We placed no restrictions on the date of publication but only considered articles published in English. We excluded questionnaires, surveys, reviews, and meta-analyses. We selected articles for final analysis per the inclusion and exclusion criteria. Secondary data that we gathered included reports from various regions of the world, differences in patient age, gender, and comparison to the nonlockdown period. We divided the studies into six regions of origin: the Americas; the United Kingdom; Europe; Asia; the Middle East; and Australia, including New Zealand. We took the mean pooled numbers from each region for comparisons between the regions and the populations studied. The reduction in the number of orthopaedic and trauma consultations and admissions estimates of odds ratio (OR) (percentage and 95\% CI). We set the level of significance at $p<0.05$. We performed all statistical analyses using SPSS Inc., version 25. We conducted this review in line with the Preferred Reporting Items for Systematic Reviews and Meta-Analyses guidelines ${ }^{12}$ and graded articles we included in the final analysis using the NewcastleOttawa Scale for the Assessment of the Quality of nonrandomised studies in meta-analyses. ${ }^{13}$ Table 1 gives the 23 studies that were part of the analysis.

\section{Results}

We identified 763 published papers on the subject. We initially analyzed 70 studies, which we retrieved using the keywords related to orthopaedic and trauma necessities and chose 23 studies for final analysis. All of them were retrospective studies, from which we could extract $50 \%$ of our preset data. These articles included 16,383 patients who sought advice related to orthopaedics and trauma during the pandemic (Figure 1). Before the pandemic, 61,559 patients sought advice for orthopaedic and trauma necessities. Most of the reports focused on adults, and in three studies, researchers did report on pandemic on paediatric orthopaedic patients. Figure 2 shows the comparison between the patients seen during and prior to the pandemic. The average decrease in patients seeking orthopaedic and trauma care during the pandemic was $45.5 \pm 20.4$ (range 18.9-86\%, $p<0.001$ ). The largest decrease in patients seeking advice occurred in Asia (60\%) and the lowest in Australia and New Zealand, at about $20 \%(p<0.001)$. As Figure 3 shows, the least cited reports on orthopaedic practice occurred in the Middle East region, with a single report.

\section{Discussion}

This review shows that a global decrease occurred in consultations for orthopaedic and trauma patients during the COVID-19 pandemic and the resulting lockdown to control the infection's spread. The average decrease in patients seeking orthopaedic and trauma care during the pandemic was $45.5 \pm 20.4$. It reached $86 \%$ in Asia ${ }^{14}$ and $82 \%$ in Europe. ${ }^{22}$ Wong et al retrieved data from 7.5 million residents during the lockdown and reported a decrease in more than 85\%. Unlike in Asia, Hamill and Sawyer (2020) reported the lowest decrease in New Zealand (32.9\%), with no motor vehicle accidents. We did not observe this trend in most of the countries. In our own experience in Saudi Arabia, motor vehicle accidents were reported as frequently as home accidents.

The overall decrease in the some studies reached $90 \%,{ }^{37}$ but researchers measured this steep decline by way of surveys to assess the importance of telemedicine. ${ }^{38}$ This decrease could have occurred due to minor injuries, which would be dealt by the emergency room was taken care at home while people with serious injuries sought hospital care. During the lockdown, nonurgent traffic decreased, leading to fewer motor vehicle accidents in many European and Asian countries. ${ }^{15,33,36}$ In our centre, road traffic accidents decreased by more than $80 \% .{ }^{29}$ Also, sports-related trauma and injuries among children in playgrounds decreased due to the quarantine, as expected. However, injuries at home increased. ${ }^{19,32}$ 
Table I Data Extracted from the Published Studies

\begin{tabular}{|c|c|c|c|c|c|c|c|c|}
\hline Authors & $\begin{array}{l}\text { Age Group } \\
\text { (Years) }\end{array}$ & $\begin{array}{c}\text { No of Patients in } \\
\text { Pandemic }\end{array}$ & $\begin{array}{c}\text { Prior } \\
\text { Pandemic }\end{array}$ & $\begin{array}{c}\text { Males } \\
\%\end{array}$ & $\begin{array}{c}\text { Females } \\
\%\end{array}$ & Pediatrics & $\begin{array}{c}\text { Emergency } \\
\text { Trauma }\end{array}$ & $\begin{array}{c}\text { Drop in } \\
\text { Patients \% }\end{array}$ \\
\hline Wong \& Cheung ${ }^{14}$ & NQ & 3992 & 28,621 & NQ & NQ & NQ & 380 & 86 \\
\hline Dhillon et al ${ }^{15}$ & NQ & 263 & 611 & NQ & NQ & NQ & 298 & 56.9 \\
\hline Reddy et $\mathrm{al}^{16}$ & NQ & 754 & 2020 & NQ & NQ & 155 & 298 & 62.6 \\
\hline Yu et al ${ }^{17}$ & 76.7 & 112 & 196 & 52 & 48 & NQ & NQ & 42.8 \\
\hline Probert et al ${ }^{18}$ & 46.2 & 135 & 159 & 61 & 39 & NQ & NQ & 15 \\
\hline Hamill \& Sawyer ${ }^{19}$ & $<14$ & 57 & 85 & NQ & NQ & 57 & 57 & 32.9 \\
\hline Raitio et $\mathrm{al}^{20}$ & NQ & 379 & 1376 & 63 & 37 & NQ & 379 & 72.45 \\
\hline Hernigou et $\mathrm{al}^{2 \mathrm{I}}$ & 45.5 & 152 & NQ & NQ & NQ & 28 & 140 & 32 \\
\hline Turgut et $\mathrm{al}^{22}$ & 40.3 & 2290 & 13,086 & 631 & 805 & 838 & NQ & 82.5 \\
\hline Maleitzke et $\mathrm{al}^{23}$ & NQ & 3743 & 5864 & 631 & 451 & NQ & 1822 & 30.1 \\
\hline Luceri et $\mathrm{al}^{24}$ & 41.2 & 670 & 2558 & 44.3 & 55.7 & 62 & NQ & 26.2 \\
\hline Staunton et $\mathrm{al}^{25}$ & 55 & 159 & 291 & 45 & 55 & NQ & NQ & 45.4 \\
\hline Mitkovic et $\mathrm{al}^{26}$ & 63.7 & 86 & 106 & 44 & 56 & NQ & NQ & 18.9 \\
\hline Zagra et $\mathrm{al}^{27}$ & NQ & 664 & 2172 & NQ & NQ & $\mathrm{NQ}$ & NQ & 69.4 \\
\hline Maniscalco et $\mathrm{al}^{28}$ & 81.1 & 121 & 169 & NQ & NQ & NQ & NQ & 32.2 \\
\hline Sadat-Ali et $\mathrm{al}^{29}$ & 37.3 & 71 & 110 & 54 & 8 & 9 & 71 & 35.4 \\
\hline Mackay et $\mathrm{al}^{30}$ & 46.3 & 166 & NQ & 93 & 73 & NQ & 100 & NQ \\
\hline Sugand ${ }^{31}$ & 52.4 & 1183 & 1792 & 43.7 & 56.3 & NQ & 100 & 34 \\
\hline Sugand et $\mathrm{al}^{32}$ & NQ & 97 & 302 & 53 & 44 & NQ & NQ & 67.8 \\
\hline Park et $\mathrm{al}^{33}$ & NQ & 87 & 193 & 43 & 44 & 12 & 92 & 54.9 \\
\hline Murphy et al ${ }^{34}$ & 61 & 603 & 887 & & & 55 & 396 & 32 \\
\hline Greenhalgh et $\mathrm{al}^{35}$ & NQ & 265 & 537 & NQ & NQ & NQ & NQ & 50.7 \\
\hline Lubbe et $\mathrm{al}^{36}$ & 45 & 334 & 424 & 265 & NQ & NQ & NQ & 21.2 \\
\hline
\end{tabular}

Abbreviation: NQ, not quoted.

The COVID19 outbreak undoubtedly reduced the number of patients seeking orthopaedic and trauma care, but at the same time, more patients presented with serious injuries later than normal at the hospital because they were afraid of infection with the SARS-2 virus. One condition was hip fractures in the elderly, which put patients at a greater risk of complications if they delayed presentation. Serra-Torres et al reported that during the pandemic, patients delayed presentation by 4.1 days after suffering fractures. Studies indicated that late presentation and delayed surgery increased complications and 30-day mortality. ${ }^{39,40}$ In our study, the length delay of presentation with hip fractures in the elderly was 7 days, and we encountered postoperative infection and no mortality. Our sample was too small for us to make a conclusion regarding this matter.

Orthopaedic trauma consultations and admissions were not the only service that decreased during the pandemic. ${ }^{41}$ The provision of other services, such as emergency room visits ${ }^{42}$ and neurosurgical procedures ${ }^{43}$ also decreased. One study revealed a $63.3 \%$ reduction in operative volume among general surgery patients. ${ }^{43}$ The literature indicates that 


\section{Studies identified from data bases \\ search:743}

690 articles

excluded on

inclusion and

exclusion criteria

\section{0 studies reviewed}

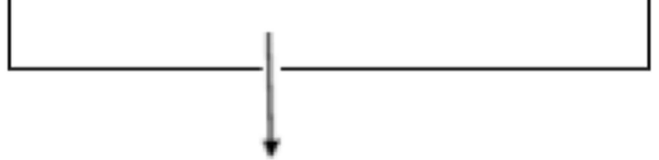
47 were excluded after full- text review due to incomplete data

\section{3 studies were finally review for Analysis}

Figure I PRISMA flow chart of the review.

orthopaedic and trauma admissions and consultations were not the only service in which consultations and surgeries decreased by more than $50 \%{ }^{44}$

This review has limitations, as we had to exclude many studies that did not provide sufficient data for inclusion in the analysis. This review's strength was that it included studies from all parts of the world, providing a global perspective of the COVID-19 pandemic's impact on orthopaedic and trauma consultations and admissions. In the future, pandemics may happen, but this one taught everyone to make a plan and be prepared if one happens again.

In conclusion, during the COVID-19 pandemic, orthopaedic and trauma surgeries, greatly decreased all over the world. The challenges have been immense in this pandemic, but we somehow adapted our entire way of thinking and taking care of patients by improvising in our work methods. In the future, pandemics may happen again, and a plan should be put in place to take care of patients who will not be able to come to hospitals for emergency and urgent care. 


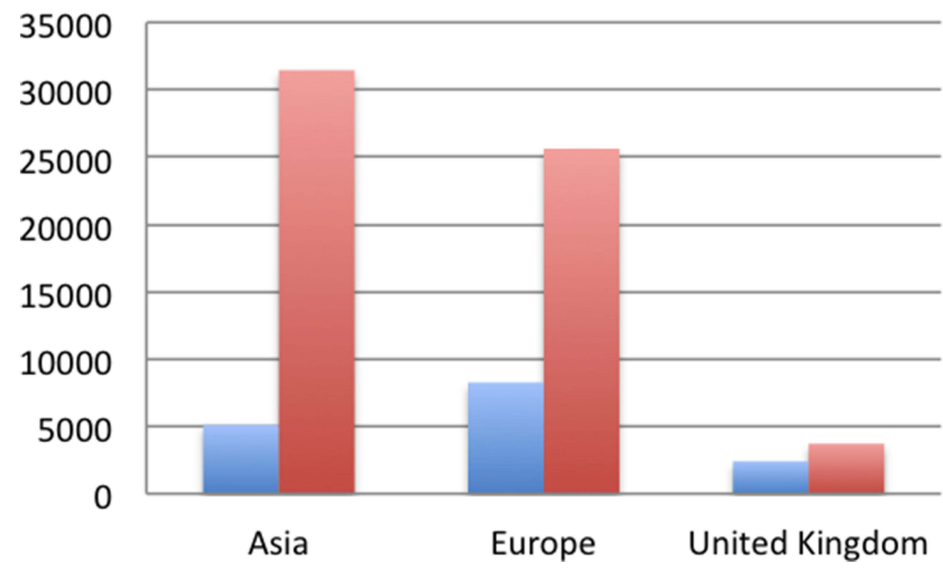

Pandemic

- Prior Pandemic

Figure 2 Data from three regions with most reports.

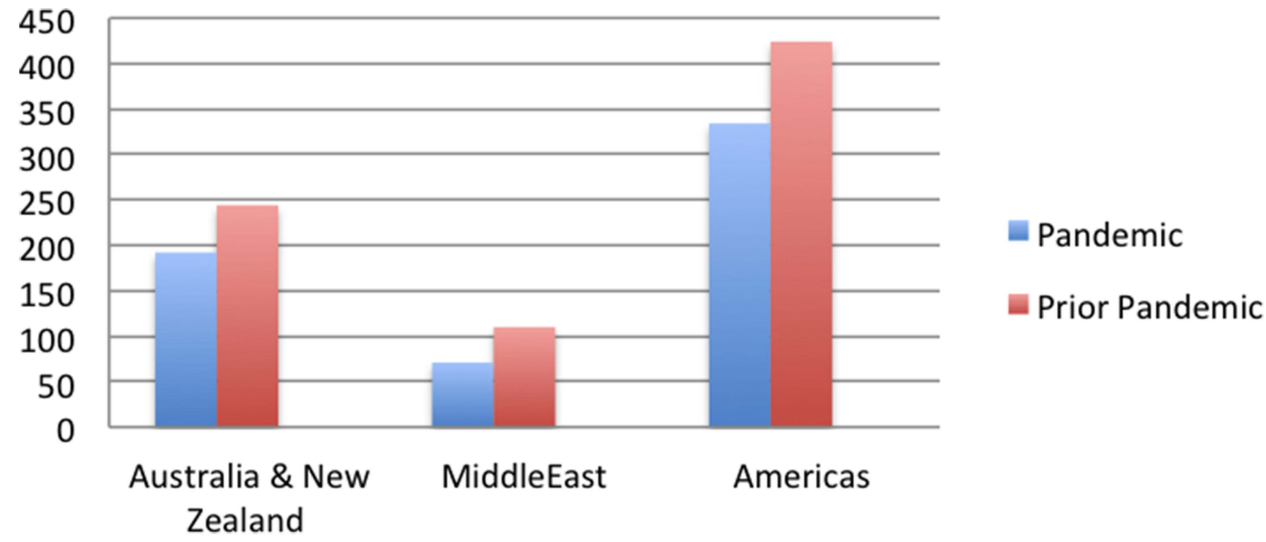

Figure 3 Regions with lowest cited reports.

\section{Disclosure}

The author reports no conflicts of interest in this work.

\section{References}

1. Zhu N, Zhang D, Wang W, et al. A novel Coronavirus from patients with pneumonia in China. N Engl J Med. 2019;382(8):727-733. doi:10.1056/ NEJMoa2001017

2. World Health Organization. Corona- virus disease (COVID-19) outbreak. Available from: https://www.who.int. Accessed January 12 , 2022

3. Rothe C, Schunk M, Sothmann P, et al. Transmission of 2019-nCoV infection from an asymptomatic contact in Germany. N Engl J Med. 2020;382 (10):970-971. doi:10.1056/NEJMc2001468

4. Lu H, Stratton CW, Tang YW. Outbreak of pneumonia of unknown etiology in Wuhan China: the mystery and the miracle. J Med Virol. 2020;92 (4):401-402. doi:10.1002/jmv.25678

5. Lu R, Zhao X, Li J, et al. Genomic characterisation and epidemiology of 2019 novel coronavirus: implications for virus origins and receptor binding. Lancet. 2020;395(10224):565-574. doi:10.1016/S0140-6736(20)30251-8

6. Guan WJ, Ni ZY, Hu Y, et al. Clinical characteristics of coronavirus disease 2019 in China. N Engl J Med. 2020;382(18):1708-1720. doi:10.1056/ NEJMoa2002032

7. Chakraborty I, Maity P. COVID-19 outbreak: migration, effects on society, global environment and prevention. Sci Total Environ. 2020;728:138882. doi:10.1016/j.scitotenv.2020

8. Raman R, Rajalakshmi R, Surya J, et al. Impact on health and provision of healthcare services during the COVID-19 lockdown in India: a multicentre cross- sectional study. BMJ Open. 2021;11(1):e043590. doi:10.1136/bmjopen-2020-043590

9. Schäfer I, Hansen H, Menzel A, et al. The effect of COVID-19 pandemic and lockdown on consultation numbers, consultation reasons and performed services in primary care: results of a longitudinal observational study. BMC Fam Pract. 2021;22(125). doi:10.1186/s12875-021-01471-3

10. Grandi G, Del Savio MC, Caroli M, et al. The impact of COVID-19 lockdown on admission to gynecological emergency departments: results from a multicenter Italian study. Int J Gynaecol Obstet. 2020;151(1):39-42. doi:10.1002/ijgo.13289 
11. Surek A, Ferahman S, Gemici E, Dural AC, Donmez T, Karabulut M. Effects of COVID-19 pandemic on general surgical emergencies: are some emergencies really urgent? Level 1 trauma center experience. Eur J Trauma Emerg Sur. 2020. doi:10.1007/s00068-020-01534-7

12. Moher D, Liberati A, Tetzlaff J, Altman DG; PRISMA Group. Preferred reporting items for systematic reviews and meta-analyses: the PRISMA statement. PLoS Med. 2009;6(7):e1000097. doi:10.1371/journal.pmed.1000097

13. The Ottawa Hospital Research Institute. The Ottawa Hospital Research Institute. Available from: http://www.ohri.ca. Accessed January 16, 2022.

14. Wong JSH, Cheung KMC. Impact of COVID-19 on orthopaedic and trauma service: an epidemiological study. J Bone Joint Surg Am. 2020;102: e80. doi:10.2106/JBJS.20.00775

15. Dhillon MS, Kumar D, Saini UC, Bhayana H, Gopinathan NR, Aggarwal S. Changing pattern of orthopaedic trauma admissions during COVID-19 pandemic: experience at a tertiary trauma centre in India Indian. J Orthop. 2020;54(Suppl 2):S374-S379. doi:10.1007/s43465-020-00241-01

16. Reddy MV, Mulpur P, Guravareddy AV, Pedamallu SK, Bhasker BV. Impact of COVID-19 pandemic on orthopaedic trauma volumes: a multicentre perspective from the state of Telangana. Indian J Orthop. 2020;54(Suppl 2):S368-S373. doi:10.1007/s43465-020-00226-Z

17. Yu P, Wu C, Zhuang C, et al. The patterns and management of fracture patients under COVID-19 outbreak in China. Ann Transl Med. 2020;8 (15):932. doi:10.21037/atm-20-4174

18. Probert AC, Sivakumar BS, An V, et al. Impact of COVID-19-related social restrictions on orthopaedic trauma in a level 1 trauma centre in Sydney: the first wave. ANZ J Surg. 2021;91:68-72. doi:10.1111/ans.16375

19. Hamill JK, Sawyer MC. Reduction of childhood trauma during the COVID-19 level 4 lockdown in New Zealand. ANZ J Surg. 2020;90:1242-1243. doi:10.1111/ans. 16108

20. Raitio A, Ahonen M, Jaaskela M, et al. Reduced number of pediatric orthopedic trauma requiring operative treatment during COVID-19 restrictions: a nationwide cohort study. Scand J Surg. 2021;110(2):254-257. doi:10.1177/1457496920968014

21. Hernigou J, Morel X, Callewier A, Bath O, Hernigou P. Staying home during "COVID-19" decreased fractures, but trauma did not quarantine in one hundred and twelve adults and twenty eight children and the "tsunami of recommendations" could not lockdown twelve elective operations. Int Orthop. 2020:1-8. doi:10.1007/s00264-019-04466-z

22. Turgut A, Arlı H, Altundağ Ü, Hancioğlu S, Egeli E, Kalenderer Ö. Effect of COVID-19 pandemic on the fracture demographics: data from a tertiary care hospital in Turkey. Acta Orthop Traumatol Turc. 2020;54(4):355-363. doi:10.5152/j.aott.2020.20209

23. Maleitzke T, Pumberger M, Gerlach UA, et al. Impact of the COVID-19 shutdown on orthopedic trauma numbers and patterns in an academic level I trauma center in Berlin, Germany. PLoS One. 2021;16(2):e0246956. doi:10.1371/journal.pone.0246956.

24. Luceri F, Morelli I, Accetta R, Mangiavini L, Maffulli N, Peretti GM. Italy and COVID-19: the changing patient flow in an orthopedic trauma center emergency department. J Orthop Surg Res. 2020;15:323. doi:10.1186/s13018-020-01816-1

25. Staunton P, Gibbons JP, Keogh P, Curtin P, Cashman JP, O’Byrne JM. Regional trauma patterns during the COVID-19 pandemic. The Surgeon. 2021;49-52. doi:10.1016/j.surge.2020.08.003

26. Mitkovic MM, Bumbasirevic M, Milenkovic S, Gajdobranski D, Bumbasirevic V, Mitkovic MB. Influence of coronavirus disease 2019 pandemic state of emergency in orthopaedic fracture surgical treatment. Int Orthop. 2020;29:1-6.

27. Zagra L, Faraldi M, Pregliasco F, et al. Changes of clinical activities in an orthopaedic institute in North Italy during the spread of COVID-19 pandemic: a seven-week observational analysis. Int Orthop. 2020;24:1-8. doi:10.1007/s00264-020-04590-1

28. Maniscalco P, Poggiali E, Quattrini F, et al. Proximal femur fractures in COVID-19 emergency: the experience of two orthopedics and traumatology departments in the first eight weeks of the Italian epidemic. Acta Biomed. 2020;91:89-96. doi:10.23750/abm.v91i2.9636

29. Sadat-Ali M, AlDakheel DA, AlOmran AS, et al. Pattern of orthopaedic trauma during Covid-19 crisis in Saudi Arabia: report from level I trauma and Covid-19 center. J Musculoskelet Surg Res. 2021;5:1-4.

30. Mackay ND, Wilding CP, Langley CR, Young J. The impact of COVID-19 on trauma and orthopaedic patients requiring surgery during the peak of the pandemic. Bone Joint Open. 2020;1(9):520-529. doi:10.1302/2633-1462.19.BJO-2020-0108.R1

31. Sugand K; C. O. V. E. R. T. Collaborative. The impact of COVID-19 on acute trauma and orthopaedic referrals and surgery in the UK: the 'golden peak weeks' of the first national multi-centre observational study. The COVid-Emergency Related Trauma and orthopaedics (COVERT) collaborative. medRxiv. 2020. doi:10.1101/2020.08.22.20179770

32. Sugand K, Park C, Morgan C, et al. Impact of the COVID-19 pandemic on paediatric orthopaedic trauma workload in central London: a multicentre longitudinal observational study over the "golden weeks". Acta Orthopaedica. 2020;91(6):633-638. doi:10.1080/17453674.2020.1807092

33. Park C, Sugand K, Nathwani D, Bhattacharya R, Sarraf KM. Impact of the COVID-19 pandemic on orthopedic trauma workload in a London level 1 trauma center: the "golden month" the covid emergency related trauma and orthopaedics (COVERT) collaborative. Acta Orthopaedica. 2020;91 (5):556-561. doi:10.1080/17453674.2020.1783621

34. Murphy T, Akehurst H, Mutimer J. Impact of the 2020 COVID-19 pandemic on the workload of the orthopaedic service in a busy UK district general hospital. Injury. 2020;51:2142-2147. doi:10.1016/j.injury.2020.07.001

35. Greenhalgh M, Dupley L, Unsworth R, Boden R. Where did all the trauma go? A rapid review of the demands on orthopaedic services at a UK major trauma centre during the COVID-19 pandemic. Int J Clin Pract. 2021;75(3):e13690. PMID: 32852851; PMCID: PMC7460967. doi:10.1111/ ijcp. 13690

36. Lubbe RJ, Miller J, Roehr CA, et al. Effect of statewide social distancing and stay-at-home directives on orthopaedic trauma at a southwestern level 1 trauma center during the COVID-19 pandemic. J Orthop Trauma. 2020;34:343-348. doi:10.1097/BOT.0000000000001890

37. Rizzi AM, Polachek WS, Dulas M, Strelzow JA, Hynes KK. The new 'normal': rapid adoption of telemedicine in orthopaedics during the COVID19 pandemic. Injury. 2020;51(12):2816-2821. PMID: 32951916. doi:10.1016/j.injury

38. Chaudhry H, Nadeem S, Mundi R. How satisfied are patients and surgeons with telemedicine in orthopaedic care during the COVID-19 pandemic? a systematic review and meta-analysis. Clin Orth Rel Res. 2021;479:47-56. doi:10.1097/CORR.0000000000001494

39. Serra-Torres M, Barreda R, Weaver D, Torres-Reveron A. Delayed Presentation of patients with hip fractures during the COVID-19 "stay-athome" order in the South most region of the United States. Adv Orthop. 2021. doi:10.1155/2021/8822004

40. Naoko Onizuka N, Topor LN, Schrodder LK, Switzer JA. Outcomes of COVID-19 negative hip fracture patients during the acute and subacute pandemic. Geriatr Orthop Surg Rehabil. 2021;12:1-8.

41. Saleem JS, Fazal MA. Fragility hip fractures in the COVID-19 pandemic: a local experience in the United Kingdom. Int J Orthop Trauma Nurs. 2021;41:100817. doi:10.1016/j.ijotn.2020.100817 
42. Pikoulis E, Koliakos N, Papaconstantinou D, et al. The effect of the COVID pandemic lockdown measures on surgical emergencies: experience and lessons learned from a Greek tertiary hospital. World J Emerg Surg. 2021;16:22. doi:10.1186/s13017-021-00364-1

43. Bajunaid K, Alatar A, Alqurashi A, et al. The longitudinal impact of COVID-19 pandemic on neurosurgical practice. Clin Neurol Neurosurg. 2020;198:106237. doi:10.1016/j.clineuro.2020.106237

44. Collins C, Mahuron K, Bongiovanni T, Lancaster E, Sosa JA, Wick E. Stress and the surgical resident in the COVID-19 pandemic. J Surg Educ. 2021;78(2):422-430. doi:10.1016/j.jsurg.2020.07.031

Orthopedic Research and Reviews

\section{Publish your work in this journal}

Orthopedic Research and Reviews is an international, peer-reviewed, open access journal that focusing on the patho-physiology of the musculoskeletal system, trauma, surgery and other corrective interventions to restore mobility and function. Advances in new technologies, materials, techniques and pharmacological agents are particularly welcome. The manuscript management system is completely online and includes a very quick and fair peer-review system, which is all easy to use. Visit http://www.dovepress.com/testimonials.php to read real quotes from published authors.

Submit your manuscript here: https://www.dovepress.com/orthopedic-research-and-reviews-journal 